\title{
Problemática epistemológica y sociológica de la teoría administrativa
}

\section{Epistemological and Sociological Problem of Administrative Theory}

\section{Problema epistemológico e sociológico da teoria administrativa}

Francisco Ballina Ríos

Universidad Nacional Autónoma de México, Ciudad de México, México

fballina@fca.unam.mx https://orcid.org/0000-0003-2739-9245

\section{Resumen}

Este artículo plantea un debate y una discusión teórica a la problemática epistemológica y sociológica de la teoría administrativa de Latinoamérica. En la primera existe una polisemia de teorías, conceptos y significados. Y en la segunda, constatamos que estas teorías provienen de contextos sociales, económicos y culturales diferentes al nuestro. El alcance del estudio radica en su aportación crítica al debate teórico; su limitante es realizar investigación empírica en cada país. La discusión se focaliza en la crítica de la teoría convencional de la administración que desde perspectivas funcionalistas y positivistas distraen las cuestiones básicas de la sociedad como el poder, la dominación, la explotación. En contraposición a estos enfoques, se describen sintéticamente algunas agendas no convencionales de investigación en administración.

Palabras clave: empresas, epistemología, filosofía, organizaciones éticas, teoría administrativa. 


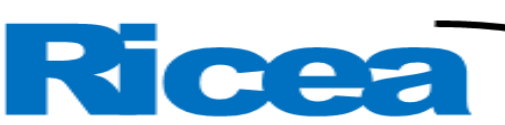

REVISTA IBEROAMERICANA DE CONTADURÍA, ECONOMÍA

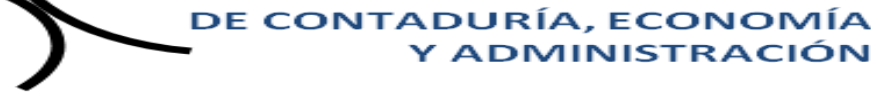

\section{Abstract}

This article raises a debate and a theoretical discussion of the epistemological and sociological problems of Latin American administrative theory. In the first there is a polysemy of theories, concepts and meanings. And in the second, we verify that these theories come from social, economic and cultural contexts different from ours. The scope of the study lies in its critical contribution to the theoretical debate; its limitation is to conduct empirical research in each country. The discussion focuses on the criticism of the conventional theory of the administration that from functionalist and positivist perspectives distract the basic issues of society such as power, domination, and exploitation. In contrast to these approaches, some unconventional management research agendas are synthetically described.

Keywords: companies, epistemology, philosophy, ethical organizations, administrative theory.

\section{Resumo}

Este artigo suscita um debate e uma discussão teórica sobre os problemas epistemológicos e sociológicos da teoria administrativa da América Latina. No primeiro, há uma polissemia de teorias, conceitos e significados. No segundo, verifica-se que essas teorias provêm de aspectos sociais, econômicos e culturais contextos diferentes dos nossos. $\mathrm{O}$ escopo do estudo reside em sua contribuição crítica para o debate teórico; sua limitação é a realização de pesquisas empíricas em cada país. A discussão se concentra nas críticas à teoria convencional da administração que, do ponto de vista funcionalista e positivista, distrai as questões básicas da sociedade, como poder, dominação e exploração. Em contraste com essas abordagens, algumas agendas não convencionais de pesquisa em gestão são descritas sinteticamente.

Palavras-chave: empresas, epistemologia, filosofia, organizações éticas, teoria administrativa.

Fecha Recepción: Enero 2019 Fecha Aceptación: Junio 2019 


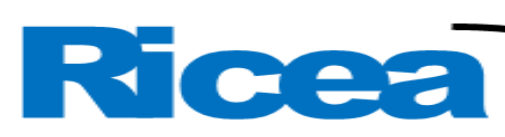

REVISTA IBEROAMERICANA DE CONTADURÍA, ECONOMÍA

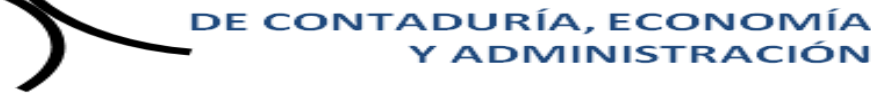

Introducción

Actualmente nos enfrentamos al hecho de que la teoría administrativa en México es casi inexistente, puesto que los centros universitarios de administración retoman teorías provenientes del extranjero, que tienen una orientación distinta a nuestra realidad y cultura, y que además no tienen fundamentos científicos bien establecidos. Los modelos gerenciales en los que se basa la teoría administrativa parten del liberalismo económico, los cuales provienen de forma dominante de Europa y Estados Unidos.

Desde la década de los 60, los métodos de organización estratégica japoneses se han puesto de moda; estos se caracterizan por promover la identificación del trabajador con la empresa y por enfatizar el papel de la motivación en pro de optimizar la productividad, utilizando para ello términos como excelencia directiva, círculos de calidad, administración por objetivos (APO), justo a tiempo, etcétera.

Esta centralización geográfica de los estudios limita su alcance y cobertura. Solo recientemente el análisis de las empresas y organizaciones se ha ampliado a otras latitudes; sin embargo, ha prevalecido el empleo de métodos y técnicas ortodoxas. De ahí la importancia de generar contribuciones teórico-metodológicas que, desde un enfoque crítico, nos permitan hacer un análisis alternativo de los fenómenos administrativos y organizacionales, cuyas explicaciones se ajusten a la realidad latinoamericana.

El estudio de las organizaciones ha sido un aspecto difícil de abordar por parte de la teoría administrativa, dado que es un campo multidisciplinario en donde convergen diferentes teorías que no siempre son compatibles entre sí.

Este artículo busca un acercamiento a la problemática de la teoría administrativa. En primer término, reconocer desde un punto de vista crítico sus categorías fundamentales, su conceptualización y su auténtica razón de ser; en segundo, describir sintéticamente hacia dónde se orientan las nuevas agendas de investigación en administración.

Todo lo anterior se hace necesario a fin de buscar una salida alternativa a la actual “jungla de la teoría de la administración”, e intentar arribar a una conceptualización de la administración cuya validez sea universal, y que contemple postulados que realmente satisfagan las necesidades actuales y futuras del hombre.

Este trabajo considera fundamental encontrar una justa dimensión del papel que en nuestra sociedad juegan las empresas y las organizaciones, y dentro de ellas los concretos y comprobables procesos administrativos y organizacionales, para con ello definir su perfil real y deseable en cuanto a métodos y ética, particularmente en relación 


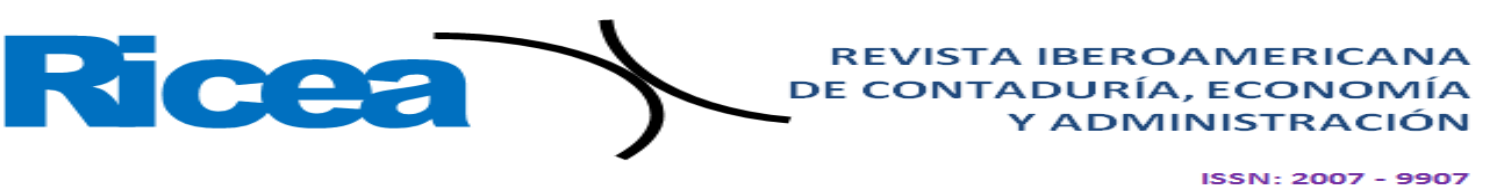

con nuestro contexto latinoamericano, y mejor aún en lo que nos atañe como sociedad y como país.

\section{Metodología}

Con frecuencia se concibe al método únicamente como el instrumento que utiliza la teoría administrativa para sistematizar una serie de pasos. Esto es un grave error, ya que, si bien el método nos sirve para esa finalidad, este va a descubrir, no a crear la realidad concreta. Así, debe brindarnos ante todo una visión del mundo para penetrar en la esencia de las cosas, descubrir la razón de ser de los procesos y entender su desarrollo y transformación. Sin embargo, todo método contiene un sustrato filosófico determinado, y cada corriente filosófica es una visión del mundo.

Cada metodología nos brinda los supuestos epistemológicos que van a conformar una teoría del conocimiento en donde podemos detectar diferentes grados de cientificidad. De tal manera que los cuestionamientos iniciales que debe hacerse todo aquel que se va a dedicar a la investigación en las disciplinas administrativas son: 1) La concepción del mundo que se adoptará, y 2) con base en esta concepción ¿cuáles serán los instrumentos metodológicos de los que se va a valer para comprender dicha realidad?

La necesidad epistemológica que tiene la teoría administrativa de estudiar y explicar los procesos y fenómenos en nuestra área de estudio nos lleva a recurrir a las ciencias sociales. Ello ha provocado que se confunda el método con la teoría y la filosofía de estas disciplinas, pues se pierde la razón de ser de cada una de ellas porque se les trata de convertir en métodos en sí mismas.

También hay quienes se inclinan por un eclecticismo metodológico: consideran que el ser eclécticos facilita las investigaciones, sin importarles que se den rupturas epistemológicas en sus discursos científicos.

Los principios epistemológicos de la teoría administrativa van a estar dados por la concepción temática del mundo, proveniente en sus aspectos ontológico (suposiciones más profundas de la realidad) y gnoseológicos de los principios empíricos de diversos campos del conocimiento. Esto significa que nuestras suposiciones ontológicas adquirirán veracidad científica al demostrar cognoscitivamente el tipo de relaciones, mecanismos y procedimientos que se dan en la realidad. Esto sucede así porque lo que se aprueba o desaprueba no son los hechos del nivel óntico, sino las representaciones gnoseológicas.

Debemos observar aquí que la espontaneidad del conocimiento es el atributo de algunos actos de voluntad del individuo. Es el hombre quien es libre, a veces, de dirigir como quiere su mirada o su pensamiento, su atención, su cuerpo, gobernando así sus 


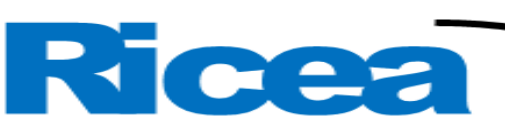

REVISTA IBEROAMERICANA DE CONTADURÍA, ECONOMÍA

conocimientos. He aquí por qué la epistemología significa criticar, escoger, elegir, por lo tanto, juzgar el valor del conocimiento verdadero.

A este respecto, en todo proceso cognoscitivo se establece un objeto de estudio en nuestro caso las empresas y organizaciones-, su observación y medición, la cual produce una imagen en el campo empírico. En este nivel de análisis ya es posible distinguir la perspectiva epistemológica utilizada por el observador, el cual transforma, a través de ciertos medios o herramientas teórico-metodológicas, la imagen o el constructo teórico del objeto de estudio. Llegado a este punto, el conocimiento organizado se logra a través de la retroalimentación cíclica de las formas epistemológicas con la realidad, con los modelos, con los constructos teóricos confrontados con el campo empírico, en un proceso de retroalimentación.

En ese sentido existe una interrelación diferente entre el objeto de estudio y las diferentes imágenes organizacionales, a través de distintas corrientes epistemológicas: escepticismo, racionalismo, idealismo, realismo y empirismo.

Es por ello por lo que el debate del ser o no ser de la administración implica descubrir en qué sentido existe. Hay que delimitar el lenguaje del deber ser del ser. Y todo ello conlleva deslindar los perfiles ideológicos, económicos y culturales de donde proceden las diferentes teorías y enfoques, evidentemente vinculados con los grupos de poder que los generan.

Las ciencias sociales construyen conceptos que tienen cierta utilidad tanto clasificatoria, terminológica y humanística; pero en la mayoría de los casos son construcciones típico-ideales que proceden de la realidad; además, son aproximaciones convencionales. Conceptos como empresa, organización, sociedad anónima, administración, liderazgo son representaciones que en parte existen y en parte se convierten en un deber ser (o también en lo que no debe ser).

Dicho todo esto, a continuación nos ocuparemos en clarificar los conceptos generales de administración y organización, para después advertir las diferencias entre organizaciones y empresas, y la función que dentro de estas últimas desempeñan las relaciones de poder y dominación. 


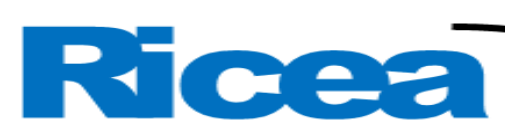

REVISTA IBEROAMERICANA DE CONTADURÍA, ECONOMÍA Y ADMINISTRACIÓN

\section{Discusión}

Desde el punto de vista de la teoría crítica, habría que distinguir el discurso abstracto, el discurso de las categorías y el de los conceptos que son presentados por la teoría administrativa, así como los móviles y significados a través de los cuales se combina este discurso, que en muchos casos no son más que palabras o ficciones que existen por convención.

Analicemos el propio significado etimológico de la palabra administración, que proviene del latín ad ('dirección', 'tendencia') y minister ('subordinación' u 'obediencia'), y que significa 'el cumplimiento de una función bajo el mando de otro'. Aquí no se contempla la diversidad de este vocablo en diversos contextos históricos y geográficos. El concepto de administración se convierte, de esta forma, en un concepto por investigar y, más aún, por corroborar.

En este sentido, lo único real, como lo ha señalado Lilienthal (1967), son los administradores, individuos de carne y hueso, que interactúan en la coordinación de empresas y organizaciones, en diversos contextos históricos y geográficos. Los administradores coordinan recursos humanos y materiales; de ello se derivan las más variadas experiencias para la conclusión de fines preestablecidos.

Ha sido reiteradamente señalada la multiplicidad y ambigüedad de la teoría administrativa con el vocablo jungla acuñado por Koontz y O’Donnell (1991, pp. 27-29), quienes, por cierto, contribuyen a incrementar esa confusión al no distinguir claramente entre las teorías y los enfoques de la administración que intentan sistematizar en su propuesta de "enfoque operacional" (p. 44); propuesta en la que reúnen conceptos, principios, técnicas y conocimientos de todos los enfoques administrativos, intentando conjuntar la teoría con la aplicación práctica.

Sin embargo, este par de autores no podrá convencer a sus colegas, por ejemplo, de cómo hacer compatibles enfoques tan diversos como el "proceso administrativo" con el "enfoque de la teoría de la decisión" o el "enfoque matemático de la ciencia de la administración”. Sería formidable que las empresas encontraran una fórmula combinada entre Taylor (1978) y Senge (1997), casi imposible de concebir, como si un químico quisiera mantener el equilibrio entre agua y aceite.

El eclecticismo y la confusión aumentan si analizamos la "jungla" existente al interior de estas "teorías", como en el caso del proceso administrativo, en donde existe multitud de variantes que van desde Henry Fayol (1973), Lyndall Urwick, Koontz, O’Donnell (1964) y George Terry (1982) hasta los autores mexicanos Agustín Reyes Ponce (1996), Isaac Guzmán Valdivia (1966) y J. Antonio Fernández Arenas (1991). 


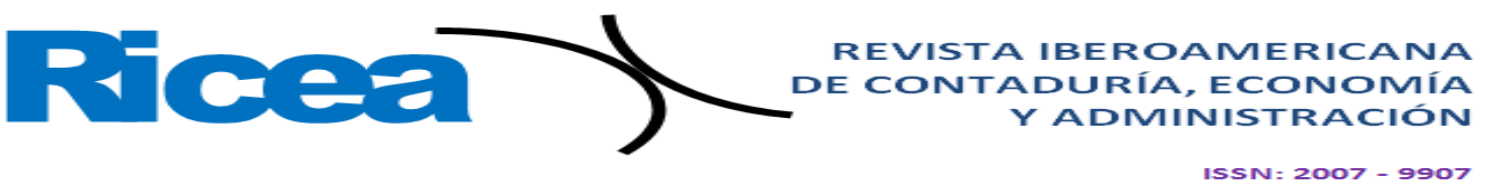

El significado y el contenido de la administración han experimentado un sinnúmero de interpretaciones. Cada una de ellas contiene alcances y limitaciones, tal y como se presenta en la tabla 1. Diferentes enfoques o nociones de la administración[.

Tabla 1. Diferentes enfoques o nociones de la administración

\begin{tabular}{|c|c|c|c|}
\hline Enfoque & Autor & Alcances & Limitaciones \\
\hline $\begin{array}{l}\text { Administración } \\
\text { como proceso } \\
\text { administrativo }\end{array}$ & $\begin{array}{l}\text { Henry Fayol } \\
\text { L. Urwick } \\
\text { L. Gu } \\
\text { G. Terry } \\
\text { Otros }\end{array}$ & $\begin{array}{l}\text { Estableció los } \\
\text { principios funcionales } \\
\text { de la empresa pública } \\
\text { y privada. Asimismo, } \\
\text { identifica las etapas } \\
\text { del proceso } \\
\text { administrativo. }\end{array}$ & $\begin{array}{l}\text { No profundiza en las } \\
\text { variables humanas de } \\
\text { la producción y el } \\
\text { trabajo. }\end{array}$ \\
\hline $\begin{array}{l}\text { La ciencia de la } \\
\text { administración }\end{array}$ & $\begin{array}{l}\text { Taylor } \\
\text { Gantt } \\
\text { Gilbreath }\end{array}$ & $\begin{array}{l}\text { Esta escuela destaca } \\
\text { la aplicación del } \\
\text { método científico, el } \\
\text { uso de la estadística y } \\
\text { técnicas cuantitativas } \\
\text { en la solución de } \\
\text { problemas } \\
\text { gerenciales. }\end{array}$ & $\begin{array}{l}\text { Es una interpretación } \\
\text { sumamente mecánica } \\
\text { de la conducta. }\end{array}$ \\
\hline $\begin{array}{l}\text { Administración } \\
\text { como profesión }\end{array}$ & Douglas McGregor & $\begin{array}{l}\text { Consiste en precisar } \\
\text { que la administración } \\
\text { es una profesión } \\
\text { relacionada con el } \\
\text { conocimiento } \\
\text { sistemático y probado } \\
\text { en la práctica. }\end{array}$ & $\begin{array}{l}\text { Es un enfoque } \\
\text { eminentemente } \\
\text { pragmático. }\end{array}$ \\
\hline $\begin{array}{l}\text { El administrador } \\
\text { sujeto de la } \\
\text { administración }\end{array}$ & $\begin{array}{l}\text { Peter M. Senge } \\
\text { Daniel Goleman }\end{array}$ & $\begin{array}{l}\text { Se preocupa por } \\
\text { definir qué es un } \\
\text { administrador, qué } \\
\text { hace, cómo distribuye } \\
\text { su tiempo, qué } \\
\text { funciones desempeña, } \\
\text { cómo optimizan el } \\
\text { trabajo, el tiempo el } \\
\text { talento, etc. }\end{array}$ & $\begin{array}{lrr}\text { Son } & \text { enfoques } \\
\text { instrumentalistas, } & \\
\text { eficientistas; } & \text { no } \\
\text { consideran } & \text { las } \\
\text { condiciones de } & \text { otros } \\
\text { agentes de } & \text { la } \\
\text { producción. } & & \\
\end{array}$ \\
\hline $\begin{array}{l}\text { La administración } \\
\text { como institución }\end{array}$ & Peter Drucker & $\begin{array}{l}\text { Considera la gerencia } \\
\text { (management) } \\
\text { uno de los mós } \\
\text { importantes } \\
\text { acontecimientos de } \\
\text { nuestra era. Coloca a } \\
\text { las grandes } \\
\text { corporaciones } \\
\text { organizaciones como } \\
\text { planes del nuevo } \\
\text { orden mundial }\end{array}$ & $\begin{array}{l}\text { Es notoria su falta de } \\
\text { objetividad. }\end{array}$ \\
\hline
\end{tabular}




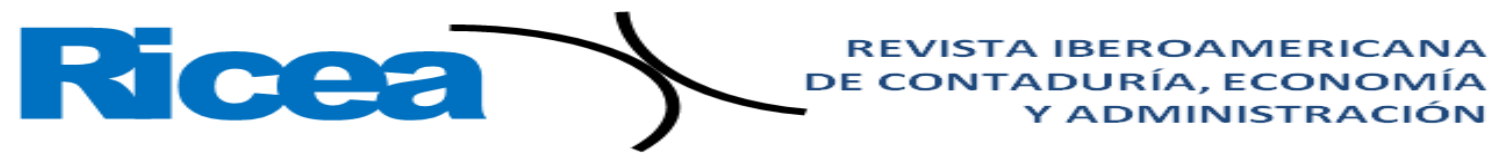

\begin{tabular}{|c|c|c|c|}
\hline & & & \\
\hline $\begin{array}{l}\text { Administración } \\
\text { como arte }\end{array}$ & $\begin{array}{l}\text { Administradores } \\
\text { empíricos }\end{array}$ & $\begin{array}{l}\text { Destaca la experiencia } \\
\text { como forma de } \\
\text { aprendizaje y } \\
\text { entretenimiento de los } \\
\text { administradores. }\end{array}$ & El empirismo limita. \\
\hline $\begin{array}{l}\text { Administración y } \\
\text { toma de decisiones }\end{array}$ & Herbert A. Simón & \begin{tabular}{l}
\multicolumn{3}{l}{ Lo que destaca de este } \\
enfoque es la \\
perspectiva micro en \\
la que actúa el \\
administrador \\
diferencia a \\
economista y la toma \\
de decisiones.
\end{tabular} & $\begin{array}{l}\text { El problema de este } \\
\text { enfoque es que no } \\
\text { distingue el aspecto de } \\
\text { la subjetividad en la } \\
\text { toma de decisiones. }\end{array}$ \\
\hline $\begin{array}{l}\text { Administración } \\
\text { como ideología } \\
\text { gerencial }\end{array}$ & $\begin{array}{l}\text { Richard Bendix } \\
\text { S. Lipset } \\
\text { G. Germani }\end{array}$ & $\begin{array}{l}\text { Hace explícito que la } \\
\text { administración se } \\
\text { centra en las } \\
\text { relaciones obrero- } \\
\text { patronales en las } \\
\text { nuevas condiciones } \\
\text { sociales, económicas } \\
\text { y tecnológicas. }\end{array}$ & $\begin{array}{l}\text { Estas "ideologías } \\
\text { gerenciales" o } \\
\text { "administrativas" } \\
\text { terminan por justificar } \\
\text { los intereses de las } \\
\text { clases dirigentes. }\end{array}$ \\
\hline Enfoque & Autor & Alcances & Limitaciones \\
\hline $\begin{array}{l}\text { Administración } \\
\text { como motivación de } \\
\text { las relaciones } \\
\text { humanas }\end{array}$ & $\begin{array}{l}\text { Douglas McGregor } \\
\text { William Ouchi }\end{array}$ & $\begin{array}{l}\text { Esta concepción } \\
\text { busca controlar las } \\
\text { emociones humanas y } \\
\text { encaminar los } \\
\text { esfuerzos en interés } \\
\text { de fines económicos }\end{array}$ & $\begin{array}{l}\text { Son modelos que } \\
\text { fueron una respuesta a } \\
\text { las necesidades de sus } \\
\text { tiempos; de ellos no se } \\
\text { desprende una teoría } \\
\text { sólida. }\end{array}$ \\
\hline $\begin{array}{l}\text { La administración y } \\
\text { la historia } \\
\text { empresarial }\end{array}$ & $\begin{array}{l}\text { Max Weber } \\
\text { Lewis Coser }\end{array}$ & $\begin{array}{l}\text { La administración } \\
\text { desde una perspectiva } \\
\text { histórica; señala el } \\
\text { surgimiento de la } \\
\text { clase empresarial. }\end{array}$ & $\begin{array}{l}\text { Su grado de } \\
\text { complejidad. }\end{array}$ \\
\hline $\begin{array}{l}\text { La administración y } \\
\text { las relaciones de } \\
\text { clase y control de los } \\
\text { asalariados }\end{array}$ & $\begin{array}{l}\text { Ralph Dahrendorf } \\
\text { André Gorz }\end{array}$ & $\begin{array}{l}\text { Corriente de carácter } \\
\text { histórico con énfasis } \\
\text { en la explotación y } \\
\text { dominación. } \\
\text { distintivo do de la } \\
\text { administración es el } \\
\text { control y se da en } \\
\text { condiciones } \\
\text { antagonismo. }\end{array}$ & $\begin{array}{l}\text { Es una corriente acorde } \\
\text { a las circunstancias de } \\
\text { explotación y } \\
\text { dominación vigentes. }\end{array}$ \\
\hline $\begin{array}{l}\text { Enfoque de la teoría } \\
\text { general de sistemas }\end{array}$ & $\begin{array}{l}\text { Michel } \\
\text { G. Morgan, G, } \\
\text { Fremont Kast, } \\
\text { R. Hall }\end{array}$ & \begin{tabular}{lrr} 
El objetivo de la & la \\
administración & es \\
conocer & & las \\
limitaciones y & los \\
objetivos que dan & dugar al sistema total \\
lugarar & \multicolumn{2}{c}{ proponer } \\
para los &
\end{tabular} & $\begin{array}{l}\text { Cualquier enfoque } \\
\text { sistémico que trate de } \\
\text { dar soluciones a los } \\
\text { problemas sociales } \\
\text { quedará limitado por su } \\
\text { contexto. }\end{array}$ \\
\hline
\end{tabular}




\begin{tabular}{|c|c|c|c|}
\hline & & $\begin{array}{l}\text { problemas que se } \\
\text { presentan. }\end{array}$ & \\
\hline $\begin{array}{l}\text { La administración } \\
\text { como objeto de } \\
\text { conocimiento de la } \\
\text { economía social }\end{array}$ & $\begin{array}{l}\text { Bernardo Kliksberg } \\
\text { Carlos Dávila } \\
\text { Fernando Cruz } \\
\text { Francisco } \\
\text { Ballina }\end{array}$ & $\begin{array}{l}\text { Lo que destaca de este } \\
\text { enfoque es la } \\
\text { administración } \\
\text { cooperativa. }\end{array}$ & $\begin{array}{l}\text { El problema es su falta } \\
\text { de difusión en el medio } \\
\text { académico. }\end{array}$ \\
\hline $\begin{array}{l}\text { La administración y } \\
\text { la ciencia del caos }\end{array}$ & $\begin{array}{l}\text { Benoit Mandelbrot } \\
\text { Mitchell Feigenbaum } \\
\text { Edward Lorenz } \\
\text { Michel Henon }\end{array}$ & $\begin{array}{l}\text { La ciencia del caos } \\
\text { puede ser una gran } \\
\text { contribución para que } \\
\text { la compleja tarea de } \\
\text { administrar se haga } \\
\text { con perspectivas más } \\
\text { amplias. }\end{array}$ & \begin{tabular}{lcr}
\multicolumn{2}{l}{ La turbulencia } & se \\
convierte & en & el \\
cementerio & de & las \\
teorías. & &
\end{tabular} \\
\hline $\begin{array}{l}\text { Administración } \\
\text { estratégica }\end{array}$ & $\begin{array}{l}\text { Igor Ansoff } \\
\text { Henry Mintzberg } \\
\text { Michael E. Porter }\end{array}$ & $\begin{array}{l}\text { La administración } \\
\text { estratégica propone } \\
\text { que los } \\
\text { administradores son } \\
\text { los elementos } \\
\text { centrales del cambio } \\
\text { organizacional. }\end{array}$ & $\begin{array}{l}\text { Una estratégica } \\
\text { requiere una } \\
\text { perspectiva hacia el } \\
\text { futuro, más que una } \\
\text { reflexión sobre el } \\
\text { pasado. }\end{array}$ \\
\hline
\end{tabular}

Fuente: Elaborado propia

Cada una de estas orientaciones contiene sus alcances y limitaciones. Lo cierto es que estos conceptos no solucionan el problema de la universalidad del objeto de estudio de la administración. De ahí que estas definiciones resulten arbitrarias, aunque pretenden trascender la ambigüedad existente en el ámbito académico respecto de acordar aquello que se estudia particularmente: la administración.

La técnica administrativa en cada caso se desarrolla en una sociedad con un proyecto histórico determinado, donde los intereses dominantes y la dirección del progreso técnico y científico se encuentran dominados por intereses de grupo.

A lo largo de la historia, las grandes organizaciones de la sociedad civil y la sociedad política se han ido adaptando y desarrollando conforme a diferentes paradigmas organizacionales que surgen de diferentes visiones o corrientes filosóficas y epistemológicas. Las imágenes organizacionales y, en su caso, las empresariales, varían en función de los diferentes constructos teóricos. Estos constructos, que en realidad se convierten en diferentes ideologías empresariales, generan a su vez diferentes imágenes del administrador y de la administración (Ballina, 2001, pp. 4-6).

La teoría convencional de la administración toma como referencia la concepción positivista de la historia, y ubica al papel de la administración dentro de un proceso organizado sobre principios burocráticos y racionales. Diferentes autores conciben el 


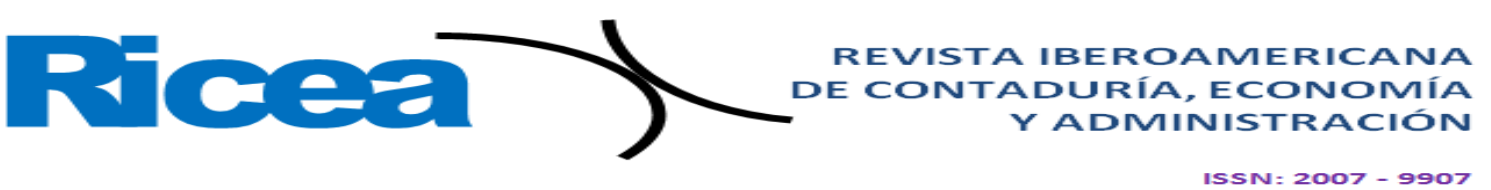

premodernismo, el modernismo y posmodernismo en función del surgimiento de la denominada administración científica de F. Taylor (Boje y Dennehys, 1993).

La “administración científica” acuñada por Taylor se basó en estudios de tiempos y movimientos. Establecía que el método científico podía ser aplicado en la selección, adiestramiento y capacitación de los trabajadores para lograr un nivel de eficiencia en la producción. El autor define la como "ciencia, y no regla empírica; armonía, y no discordia; colaboración, y no individualismo; rendimiento máximo, en lugar de rendimiento restringido; formación de cada hombre hasta alcanzar su mayor eficiencia y prosperidad" (Frederick, 1978, p. 121).

El error de Taylor reside en pensar que, de la simple aplicación del método científico en el estudio de tiempos y movimientos en los procesos industriales, pudiera surgir a priori la "administración científica". Los principios de la ciencia no pueden estar estructurados de forma que puedan servir como instrumentos conceptuales para un universo de controles productivos.

Tolstoi, en alguna ocasión, afirmó que "la ciencia era vacía porque no daba contestación a la pregunta ¿qué haremos y cómo viviremos?’. Parece que la ciencia no contesta a dichas preguntas, y que solo ayuda a interpretar el sentido que lleva el mundo; averigua el curso de la naturaleza, pero no puede impartir órdenes al hombre; responde al qué y para qué, pero no debe imponer el cómo, porque eso va en razón del hombre y sus circunstancias.

La ciencia está vinculada con la producción y la administración. La aplicación de esta en forma de técnicas a la investigación se convirtió en la sustancia permanente del mundo de trabajo industrial donde vivió Taylor. De la misma manera, se ha convertido en la sustancia del mundo moderno y posmoderno de los países productores de ciencia y tecnología. Solo Estados Unidos, Europa y algunos países asiáticos son productores de ciencia y tecnología, los demás son consumidores. Debido a lo anterior, ni una ni otra pueden tener el mismo valor en África, Alemania o México. La ciencia y la técnica son en cada caso un proyecto histórico en el que se proyecta una sociedad y los intereses dominantes de ella. La tecnología, por su parte, es un cierto tipo de producción y de desarrollo estratégico al que se pretende llegar.

La propuesta teórico-metodológica de Taylor nunca prosperó al nivel de cientificidad debido a su carácter extralógico e ideológico de concebir que la “administración científica" pudiera ser "universalizable". Sin embargo, generó nuevos puntos de vista, promovió un ambiente de investigación, una nueva era de cooperación, 


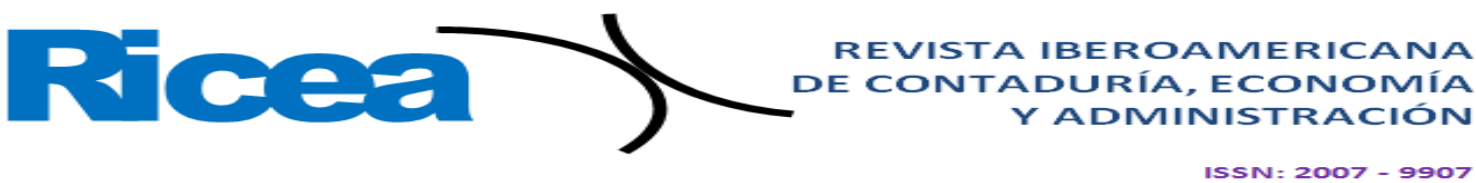

de rudo individualismo y espíritu colonizador, y marcó los hitos convencionales del modernismo administrativo.

Como contrapartida a esta propuesta, surgió el modelo de las relaciones humanas como una reacción a la cosificación del empleado, y se puso énfasis en la especialización y en el grupo y su efecto dentro de la organización, al señalar aspectos tales como condiciones propicias del medio ambiente social y material que satisfagan las necesidades de los trabajadores.

El significado de la administración ha experimentado desde principios del siglo XX un sinnúmero de interpretaciones. Hoy en día se le ha conceptualizado como el proceso a través del cual se dirigen los recursos humanos, materiales y financieros para la consecución de ciertos objetivos, pero muy especialmente para mantener complacido al cliente, quien es el que permite seguir viviendo y desarrollando a la empresa.

La teoría de la burocracia estructuralista continúa en la línea de la especialización de actividades, tanto en la organización formal como informal. Otros enfoques más recientes hacen énfasis en la dirección o gerencia de individuos interrelacionados, o bien la refieren al proceso administrativo, clasificándola como ciencia o arte (Cruz, 1988).

En el caso de la formación de gerentes, el graduado en administración de negocios piensa que la administración es un fin en sí mismo, una habilidad relativamente independiente del contenido de aquello que se administra; piensa que la técnica es más importante que el objeto a la que se aplica.

En la teoría administrativa prevalecen los enfoques gerenciales de Europa, Estados Unidos y Japón, como ya se mencionó al inicio de este texto. Esto ha sucedido así porque la estructura de la producción científica está determinada por la inercia de la estructura institucionalizada del modo capitalista de producción; el funcionamiento de la ciencia abstracta actúa como medio para fines predeterminados, externos, enajenados.

En Estados Unidos, la comunidad académica en su conjunto está normalmente abierta a las oportunidades, por decirlo así, que le ofrecen ser experta en la interioridad de las máquinas administrativas y poner en "venta" sus recomendaciones. Otro problema de las disciplinas administrativas es el fetichismo por el concepto, y el formalismo estadístico, de precisión y exactitud. El empirismo abstracto intenta estandarizar y racionalizar cada fase de la investigación, especialmente en el marketing, tanto en el sector público como en el privado, para sus fines burocráticos.

En resumen, se concluye que la problemática de la teoría administrativa se encuentra en dos niveles: por una parte, en el epistemológico, por el hecho de que diversas teorías le atribuyen a un mismo concepto significados distintos; por otra, en el nivel 


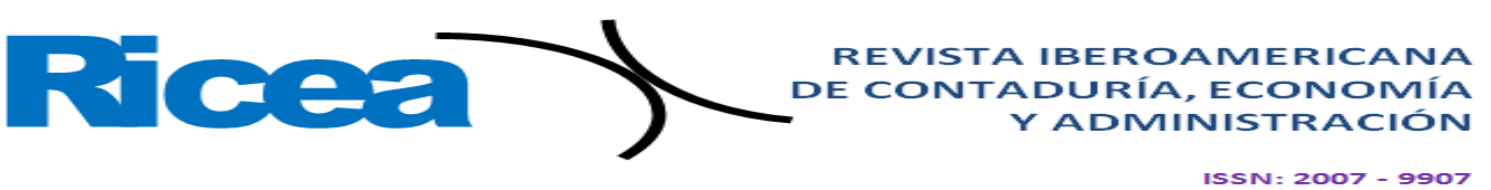

sociológico se constata que esas teorías se inscriben en circuitos sociales distintos de producción y consumo, lo que deriva en su falsa generalización en diferentes ámbitos geográficos.

El problema epistemológico de la teoría administrativa radica en su falta de consistencia y coherencia interna. La insuficiencia teórica de su aparato conceptual adquiere un carácter ideológico debido a sus motivaciones extrateóricas: aspiraciones, propósitos y proyecciones de diferentes intereses: económicos, políticos, de clase, raciales, etcétera. Es decir, se atienden intereses ideológicos en pro de grupos dominantes.

La denominada teoría de la administración (management science) surgida del contexto liberal anglosajón y la teoría de la organización (organizations theory) (Jo Hatch, 1997) consideran a las empresas (companies) y organizaciones (organizations) como entes similares; son concebidas como comunidades o sociedades, relativamente permanentes, orientadas hacia un mismo objetivo, enfocadas en la acción organizacional, como conjunto de órganos y funciones (Merton, 2002).

Los autores mexicanos que han incursionado en el análisis de la teoría de la administración, basados en la lectura de Parsons (The social system, 1951), y en una mala traducción y distorsión que se hizo de la obra de Weber (Montaño, 2004; Cruz, 2013; Ríos, 1990), han incurrido en el mismo error que toma como sinónimo a empresas y organizaciones, lo que genera confusión y ambigüedad en los términos poder y dominación.

A este respecto, la teoría administrativa convencional confunde la organización con lo que es la empresa. En general, los autores que siguen esta teoría lo que hacen es ignorar las relaciones de poder a nivel macro-micro, implícitas en las organizaciones y empresas.

Así, pues, existe ambigüedad en el concepto organización; algunas veces es utilizado como función, consistente en agrupar actividades necesarias para el cumplimiento de objetivos; en otras, como estructura-diseño: decisión estratégica; o bien como actividad específica para diseñar y estructurar las tareas encaminadas a lograr las metas organizacionales (Dessler, 1996).

Toda la literatura posweberiana sobre la burocracia padece de esa ambigüedad. Por un lado, la mayoría de los autores creen que el desarrollo de las organizaciones burocráticas responde al advenimiento de la racionalidad en el mundo moderno; y por otro, creen que la burocracia es, por ese hecho, intrínsecamente superior a todas las formas posibles de organización. 


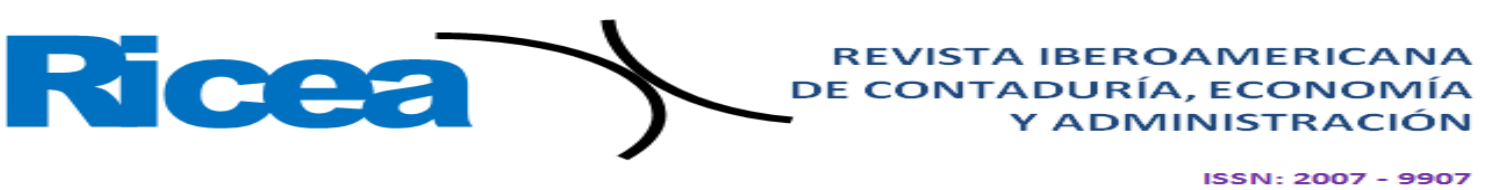

Mills (1961, pp. 44-47) cuestionó la obra de Parsons a partir de su afirmación de que no existe la ciencia social "neutra", al distraer las cuestiones básicas de la sociedad como el poder y la dominación. Este autor y la secuela de autores basados en su obra ocultan las realidades estructurales de la sociedad misma.

Algunos autores, como M. Reed (1992), puntualizan que, en general, en el estudio de las organizaciones se ha tenido una pérdida de confianza en las aproximaciones positivistas y funcionalistas, pues estas corrientes no han mostrado resultados que respondan a la problemática del poder, de la dominación y de la explotación.

Por ello es importante revisar algunos conceptos básicos del poder, que derivan de diferentes ángulos. Para Weber $(1922,1969)$, el poder y la dominación son plenamente distinguibles, ya que no hay dominación sin aparato administrativo; es decir, institución, organización, cuadros que administren la forma específica de dominación.

En la organización, la dominación se entiende como la probabilidad de encontrar obediencia a un mandato de determinado contenido entre personas dadas. En otros términos, es la probabilidad de que un mandato sea obedecido por una parte o por un conjunto de personas (sin olvidar las funciones de las normas y los valores) como, por ejemplo, la dominación ejercida por organizaciones eclesiásticas en sus respectivos ámbitos geográficos.

La sociedad se desenvuelve bajo la influencia de diferentes organizaciones, como familia, iglesia, ejército, partidos políticos, sindicatos, oficinas gubernamentales, prisiones, etcétera, respondiendo a necesidades y contextos específicos, tomando muy diversas formas y representando distintos sistemas de valores dentro del complejo social.

De acuerdo con Max Weber (1969), la organización tiene una función reguladora, limitadora hacia fuera, y a través de ella se caracteriza una relación de supremacía y subordinación. En toda organización participa un círculo de personas interesadas en el mandato y sus ventajas, que colabora así en el ejercicio de los poderes imperativos y coactivos encaminados a la conservación de la dominación.

La organización se relaciona con la expansión del poder, es decir, la organización tiene que ver con el control hacia afuera, sus acciones permean a otras instancias. Por otro lado, el concepto de poder en la empresa está estrechamente relacionado con acciones que se vierten hacia adentro.

Todas las formas de dominación son vitales para el mantenimiento de la existencia de las organizaciones y su acción está dirigida a la realización de la imposición de los ordenamientos. La dominación es una relación y, como tal, si no se ejercita no existe: en un momento determinando un individuo puede estar condicionando su comportamiento 


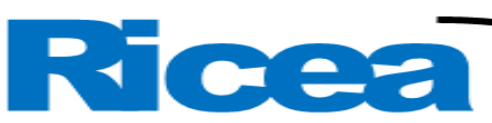
de influencia”. La dominación incluye especificidad en el contenido del mandato (obediencia). El que obedece transforma el mandato en la razón de su conducta y, cuando eso ocurre, hay mandato concreto y la obediencia se rige tomando como norma la voluntad del que domina.

La organización comunal es la relación de un grupo o una comunidad de personas que persiguen los mismos fines, rasgos étnicos, valores, etcétera. Su regulación depende de su tamaño y de las características de los miembros. Si el grupo es pequeño, la organización puede ser de naturaleza primaria; en tal caso, en la regulación de acciones participan todos los miembros en condiciones de equiparidad (que no es lo mismo que igualdad). En las organizaciones grandes la naturaleza de la integración es secundaria; es decir, se caracteriza por intereses que no afectan de manera íntima a sus miembros, sino a sus intereses económicos, políticos o culturales.

El dominio es una cualidad de la organización que, sustentada en recursos coercitivos, cognoscitivos, tecnológicos o financieros, está en condiciones de imponer premisas de comportamiento a otras organizaciones.

La élite norteamericana encontró en la historia moderna una burguesía virtualmente sin oposición. La guerra de secesión puso fin a las pretensiones coloniales de la nobleza, y muchos latifundios fueron repartidos. Entre 1865-1900, una minoría poderosa concentró el poder económico y financiero de los grandes trust y corporaciones, que dieron lugar a las grandes dinastías que siguen dominando hasta nuestros días: Vanderbilt, Rockefeller, Carnegie, Ford, J.P. Morgan lograron subordinar el poder militar y social bajo sus intereses (Mills, 1957).

Las articulaciones de empresas y organizaciones en Estados Unidos surgen del liberalismo económico en el mecanismo del equilibrio, con el que la libertad económica y política queda garantizada con el sistema de pesos y contrapesos.

Podríamos afirmar que entre empresas y organizaciones existe o no una correlación de fines; en ocasiones la empresa se sirve de la organización para alcanzar sus fines y viceversa.

La organización representa el poder institucionalizado, y debe contar con legitimidad y legalidad. Debe entenderse por legitimidad la aceptación por parte de los subordinados de los procesos y resultados de la organización, y por legalidad el estar de acuerdo con las normas de constitución y funcionamiento de la organización. A través del cuadro administrativo se puede lograr de un modo plural la dominación, por el poder representativo que se le confiere; es decir, la probabilidad de que se dará una actividad 


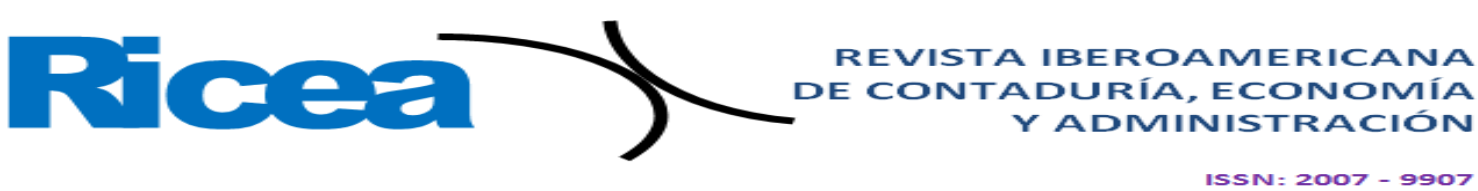

dirigida a la ejecución de las órdenes generales y mandatos concretos por parte de hombres cuya obediencia se espera.

Toda empresa implica necesariamente una forma de organización, pero una organización no implica necesariamente una empresa. Todo dominio implica el ejercicio de un poder, pero no todo poder implica el ejercicio de un dominio, ya que uno puede estar en la relación de pares; es decir, una organización puede entrar en relación de equiparidad con otra organización, en la cual no haya dominio de una sobre la otra. Pero el poder está presente.

El cuadro administrativo está ligado a la obediencia de estos motivos que determina en gran medida el tipo de administración: tribal, patrimonial o burocráticoracional.

La dominación es una relación entre dominados y dominantes y, como tal, si no se ejercita, no existe. La dominación de algún orden regulador puede ser una relación transitoria: en un momento dado el comportamiento de un individuo puede estar condicionado conforme a los preceptos de la religión católica, pero puede cambiar su conducta optando por otra religión. Otros, en alguna reunión social, podrán optar por algún tipo de indumentaria, y podrán conseguir o no que otros copien, por así decirlo, sus formas de comportamiento o de vestirse.

Para tratar de ser más precisos, podríamos afirmar que tanto una empresa u organización requieren apoyarse en una “organización” para lograr sus fines, en ese caso específico la empresa y la organización se identifican. Podemos afirmar, asimismo, que la dominación de gobiernos y pueblos extranjeros requiere del medio empresarial para alcanzar sus fines de lucro y dominación, y que a su vez las empresas requieren de las organizaciones político-militares para abrir sus mercados.

Es importante mencionar otro aspecto que distingue a las empresas de las organizaciones: la organización se relaciona con la "expansión” del poder; es decir, la organización tiene que ver con el control hacia fuera, sus acciones permean a otras instancias. Por otro lado, el concepto de poder en la empresa está estrechamente relacionado con acciones que se vierten hacia dentro.

Un ejemplo de organización sería la Secretaría de Educación Pública (SEP), entidad que dicta reglas y ordenamientos que deben ser acatados por los distintos grupos vinculados a la actividad de la educación. Por su parte, un ejemplo de empresa lo constituye el Tecnológico de Monterrey, institución que debe seguir los lineamientos establecidos por la SEP para su operación. 


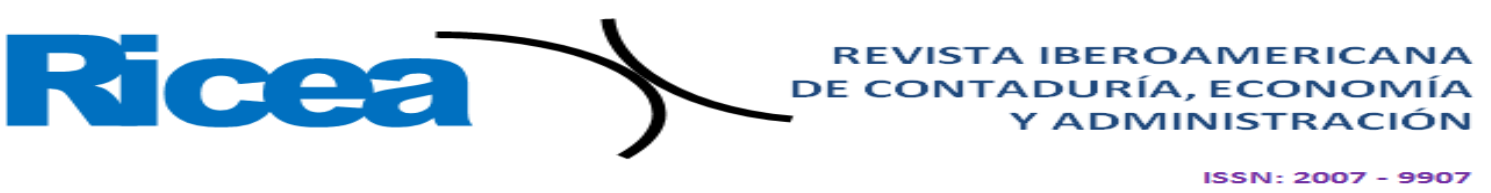

También es importante señalar, como parte de las diferencias entre empresas y organizaciones, que en la organización el concepto cuadro administrativo está más ligado al concepto de dominación, legitimado por el uso tanto de la violencia física como psíquica, como puede ser el caso de las organizaciones estatales y eclesiásticas, respectivamente. En tanto, este concepto en el caso de la empresa se liga más a la explotación, por la manera en que se consuman los medios de producción y trabajo para alcanzar el fin perseguido por las empresas mercantilistas.

Weber (1969) define la empresa como "una acción que persigue fines de determinada clase, de un modo continuo" (p. 42). Lo que la caracteriza es la acción consciente que persigue fines de una manera constante. La empresa es una asociación que tiene por objeto la elaboración de un producto o la prestación de un servicio, ya sea estatal, paraestatal, municipal, cooperativo, comunal o corporativo. Las empresas más conocidas son las de interés privado, cuyo funcionamiento declarativamente se regula por las leyes del mercado; sin embargo, Weber (1969) incluye la realización de otro tipo de actividades, a saber, las políticas, científicas o hierocráticas (religiosas), públicas, privadas, etcétera.

El concepto corriente de empresa que se maneja es el de "empresa mercantil", que solo subraya expresamente la orientación por el cálculo de capital, la mayoría de las veces supuesto como evidente; pero no solo el intento de lucro como tal debe ser llamado empresa. En sentido estricto la empresa puede ser empeño de un solo individuo, siempre que persiga sus fines de manera continua en el tiempo. La empresa, redondeando el concepto de Weber, puede también referirse a un subconjunto de empresas y asociaciones de estas tomadas conjuntamente.

Podemos observar que, desde su origen, la palabra empresa, esfuerzo de personas, tiene la intención de emprender acciones conjuntas, algo que de manera solitaria sería prácticamente imposible de conseguir.

En la gerencia de la empresa está la figura del poder, ya que tiene la posibilidad de imponer la propia voluntad dentro de una relación laboral, aun en contra de toda resistencia, imponiendo la estructura de autoridad al interior de la empresa y atendiendo a los sistemas de valores que las legitiman.

Sin embargo, a partir del ámbito de influencia en la "acción social", surge otra diferencia entre el poder y la dominación. En la dominación este ámbito es más difuso y ambiguo que el concepto de poder en lo que Weber llama influencia. Las formas de influencia, o sea, las formas en que un individuo, organización o empresa puede imponer su voluntad, son muy variadas. 


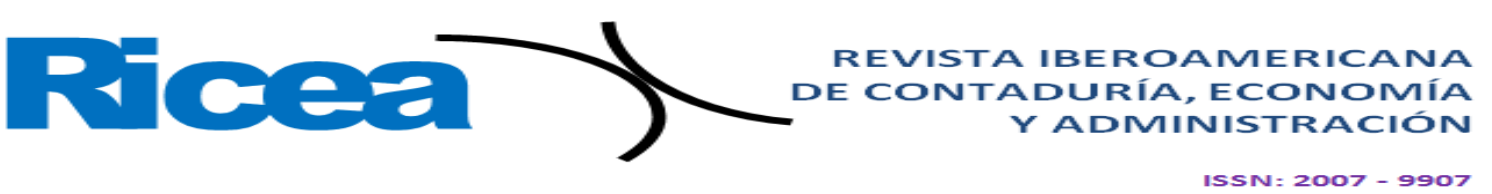

Para ser más precisos, la empresa, para lograr sus fines a lo largo del tiempo, frecuentemente trata de establecer un programa de trabajo - así sea el más simple. Por su parte, toda organización, cuyo fin es contribuir a un esquema de dominación, desea establecer su dominación no de manera efímera, sino a lo largo del tiempo, pensando que normalmente toda organización tiene como fin conservar un esquema de dominación. La empresa, a su vez, desea conservar una jerarquía de poder.

El estudio de las organizaciones se ha efectuado desde numerosos enfoques. El vacío generado por las corrientes funcionalista y positivista de la administración ha suscitado nuevas agendas de investigación como parte de la búsqueda de un entendimiento adecuado y coherente del proceso cultural, cognoscitivo, lingüístico, político e ideológico a través del cual se constituyen las organizaciones. Dentro de estos nuevos enfoques, se tienen dos grandes orientaciones.

La primera se encuentra asociada a la lectura de los clásicos: Marx y Weber, y ligada a los teóricos de la escuela de Frankfurt. Se asume que la división del trabajo y la innovación tecnológica son una consecuencia de los imperativos de acumulación y control, de los que depende la viabilidad económica de la empresa.

Con ello, la visión tradicional del consenso y cooperación en el estudio de las organizaciones se ve transformado por la visión de las clases sociales, cuyas condiciones de existencia son muy distintas a las reconocidas por los funcionalistas y positivistas.

En la segunda orientación, otro grupo de autores, partiendo de los análisis depurados de las variables políticas, económicas, filosóficas, éticas, etcétera, ubican el estudio de la administración como una totalidad histórica, tomando en cuenta elementos soslayados por la teoría convencional de la administración.

El retorno a los clásicos desde la perspectiva de Weber y Marx, las teorías del psicoanálisis y la psicología social de Erich Fromm, de Víctor Frankl con la logoterapia, y de Wilhelm Reich y su intento de vincular a Freud con Marx. En este caso se trata de investigar cómo las reglas burocráticas posibilitan la introyección de formas de pensamiento y acción que favorezcan un comportamiento despersonalizado y deshumanizado (Sprott y Johnson, 1968).

Este proceso de configuración teórica se inicia con Aristóteles, Maquiavelo y Hobbes; continúa con Hegel, Marx, Durkheim, Weber, Mosca, Pareto, la escuela de Frankfurt, y prosigue hasta nuestros días. Los diferentes constructos teóricos, neomarxismo, posestructuralismo (Baudrillard, 2004; Lyotard, 1990; Habermas, 1993), continúan con la tradición crítica. 


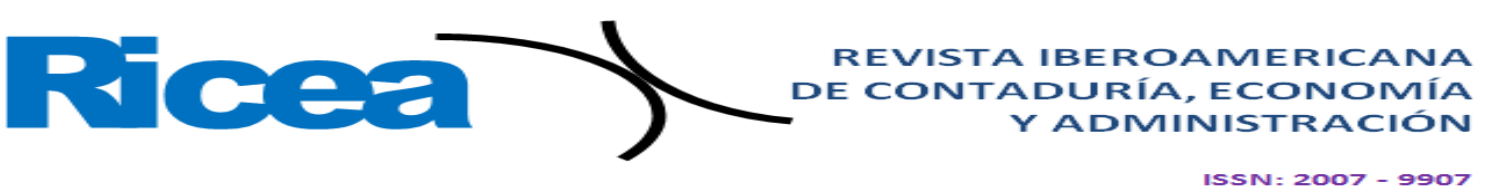

La teoría crítica se ha distinguido por estar comprometida con las nuevas condiciones sociales, políticas y económicas, como una teoría histórica y dialéctica que intenta capturar y conceptualizar los cambios históricos y evaluar el impacto de dichos cambios (Kellner, 1998).

El posmodernismo francés (Saussure, 1987; Levi Strauss, 1964; Barthes, 1994) y la nueva teoría francesa (Lyotard, Baudrillard y otros) polemizan en contra de la teoría crítica, en donde los teóricos críticos reconocen una continuidad, y existen quebrantos: el racionalismo descartiano, la autoconciencia hegeliana y el etnocentrismo liberal y marxista.

Tales quebrantos se produjeron en la antropología (el relativismo cultural), en la lingüística (Lyotard, Baudrillard, Derrida) y en el psicoanálisis (Lacan, 2008; Foucault 1970), todos ellos se oponen a la visión histórica que desaparece en la modernidad, en el "fin de la historia", el sitio "omega" de la historia, el mañana donde el hombre se reconcilia consigo mismo, con la naturaleza y la sociedad, con sus orígenes.

En la posmodernidad, los cambios no permitieron echar raíces, el progreso perdió dirección, perdió sus fines, ninguna tecnología garantiza el futuro promisorio, no se sabe hacia dónde vamos, existen una infinidad de escenarios posibles que nos esperan o que se pueden crear. Este es el gran reto del futuro.

El marco conceptual de la teoría organizacional dentro de la teoría administrativa se origina en las aguas fangosas de los fundamentos de la "administración científica" de Taylor. El objeto principal de la administración ha de ser, según Taylor, asegurar la máxima prosperidad para el patrón, junto con la máxima prosperidad para cada uno de los empleados, objetivo que no tiene fundamento científico. En la teoría neoclásica de la administración se mantiene como búsqueda el alcanzar el éxito económico de las organizaciones como último y exclusivo fin.

El problema principal reside en que la teoría administrativa le ha construido a la teoría de la organización una "jaula de hierro" en la búsqueda de los objetivos utilitarios de las organizaciones. La utilización de la teoría administrativa, clásica y neoclásica no ha servido hasta ahora más que para el estudio del tema de decisiones a nivel directivo, con criterios eficientistas, productivistas. Sin embargo, si analizamos el cuerpo sistemático de conocimientos relativos a la teoría de la organización, producto de la última década del siglo XIX y del XX, podremos constatar la rica herencia que se ha gestado a lo largo de estos años de estudio de las organizaciones humanas y de la administración de gobiernos, iglesias, ejércitos y otras organizaciones sociales complejas. 


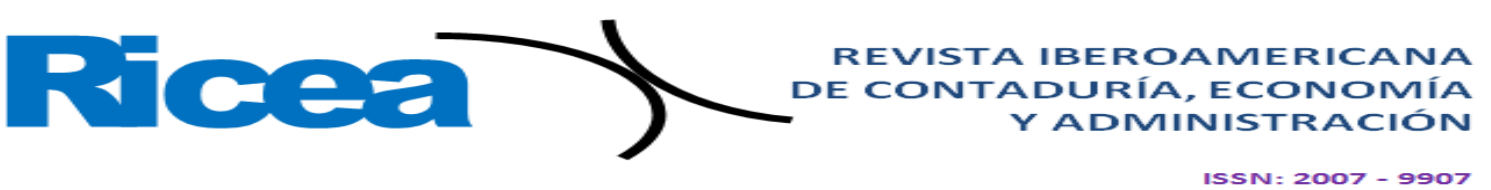

La teoría convencional de la organización —Mary Parker (1942), Herbert Simón (1981, 1982) - consideran a la organización como un sistema complejo de toma de decisiones, o como un sistema de interacciones de actividades y sentimientos (Homans, 1950), e incluso como un sistema cerrado o abierto o de contingencias.

Hay evidencias de que la teoría neoclásica de la administración no ha superado el escollo de la clásica, en términos de considerar al trabajador como simple engrane de una máquina. Los interaccionistas (Elton Mayo y colaboradores, 1989) se interesaron exclusivamente en el mundo de las interacciones-sentimientos como respuesta de productividad al condicionamiento económico del salario y del rendimiento, que es una propuesta de la "administración científica" de Taylor y Fayol. Si se demuestra que la conducta afectiva se halla condicionada por una serie de factores controlables, es difícil no servirse de semejante conocimiento para tratar de manipular a los trabajadores, y desentenderse lo mismo que los clásicos de los problemas del poder y la dominación.

Kurt Lewin (1968) y sus colaboradores (teoría de los grupos) querían demostrar que existía una relación constante y unívoca entre la satisfacción individual, la productividad y un estilo de liderazgo permisivo. Además, continuaron desconociendo las relaciones de poder y explotación que se anudan alrededor de la pirámide jerárquica y sin las cuales esta solo aparece en un marco puramente formal.

Sin duda, al atraer la atención hacia los problemas de la participación, los seguidores de Lewin (1968) introdujeron una veta de investigación que se ha revelado fecunda, pero también se encerraron en una pauta de interpretación muy estrecha, que no les permite comprender las fuerzas actuantes dentro de las organizaciones.

Robert Kahn, Arnold Tannenbaum y sus colaboradores (1971) creen que se puede llegar a coordinar las actividades humanas en el seno de una organización y, asimismo, obtener el máximo necesario de aceptación utilizando estímulos económicos o ideológicos. Se busca así la perfecta productividad y un equilibrio entre los fines de la organización y la satisfacción individual de sus miembros. Utilizando un sistema "permisivo" de mando, en esta teoría tampoco es necesario estudiar los problemas del poder; basta con luchar porque el aparato de mando no se desintegre.

Robert Michels (1969) y K. Manheim, (1982) son los primeros en destacar el dilema en que se encuentran forzosamente las burocracias modernas que quieren lograr profundas transformaciones sociales, sean reformistas o revolucionarias. La acción social no es posible sino a través de organizaciones burocráticas, y la existencia de estas es incompatible con los valores democráticos que son los únicos que hacen legitima la acción social. 


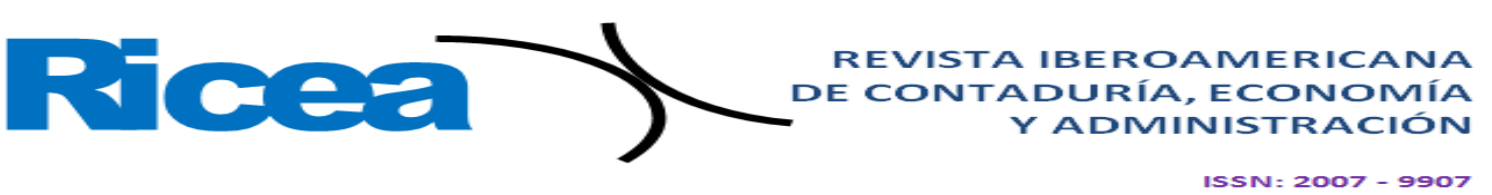

A este respecto, destaca la opinión de Chester Barnard (1959), quien conceptualiza la organización como un sistema social cooperativo; es decir, como un sistema de actividades o fuerzas sociales, biológicas y físicas conscientemente coordinadas, cuyo balance tanto interno como externo debe mantenerse en equilibrio.

No obstante, cualquier acción cooperativa coordinada exige que cada participante pueda contar con un grado de regularidad suficiente por parte de los demás. Esto significa, en otras palabras, que toda organización, cualquiera que sea su estructura, su objetivo y su importancia, requiere por parte de sus miembros una conformidad mayor o menor, pero siempre considerable y obtenida en parte por compulsión, apelando a la "buena voluntad".

El burocrático no es solamente un universo que no se corrige en función de sus errores, sino que es incapaz de transformarse conforme a la evolución acelerada de las sociedades, como lo muestra el nihilismo llevado a sus consecuencias más extremas en las proyecciones simbólicas típicas de Kafka.

Dentro de una visión sistemática (Michel, 1974), la organización debe concebirse como un sistema abierto, es decir, que tiene múltiples relaciones con el ambiente. También debe concebirse como un sistema con múltiples propósitos o funciones necesarias para integrar y coordinar. Que conlleva muchos subsistemas en interacción dinámica. Y dado que los subsistemas son mutuamente dependientes, sus cambios afectarán el comportamiento de los demás. Las múltiples relaciones entre la organización y su ambiente hacen difícil especificar de manera clara las fronteras de una entidad dada.

Desde el punto de vista del enfoque sistémico, las organizaciones son concebidas como estructuras ordenadas y esta predisposición alienta el funcionalismo que conceptualiza la realidad dentro de un marco altamente estático y mecanicista.

Desde finales de la Segunda Guerra Mundial hasta los últimos años de los 70, el consenso teórico y metodológico de los estudios organizacionales giró alrededor del funcionalismo y el positivismo, lo que proporcionó una base al poder burocrático.

En las teorías contemporáneas de la administración —enfoque operacional (McGregor y colaboradores) - y en la actual teoría de los sistemas —enfoque de las contingencias - prevalece la tolerancia y el eclecticismo, situación que se puede apreciar en los programas de estudio de las business school estadounidenses, en las que prevalece la confusión en el terreno teórico de la administración.

Estamos viviendo en un mundo que se está haciendo cada vez más complejo y sofisticado. Desgraciadamente nuestras formas de pensar, de razonar, casi nunca se adaptan a esa complejidad. La mayoría de las veces terminamos convenciéndonos a 
nosotros mismos de que todo es más simple de lo que en realidad es y manejándonos en la complejidad como si esta no existiera. El resultado es que nuestros pensamientos terminan siendo simplificaciones muchas veces perjudiciales; tal es el caso de la teoría administrativa norteamericana, que ha fracasado en su intento por formar una profesión que pueda tener un carácter de cientificidad.

En síntesis, el alcance de este artículo es el de reconocer desde un punto de vista crítico las categorías y conceptos de la teoría administrativa, así como los móviles y significados a través de los cuales se combina el discurso académico y el significado ideológico de las distintas acepciones de la administración. Como tema de investigación pendiente y limitante de este artículo, no obstante, es el de revisar los nuevos paradigmas para las empresas y organizaciones en el contexto latinoamericano. En el actual escenario geopolítico mundial nuestros instrumentos conceptuales son necesarios e incluso indispensables como puntos de llegada, pero, al mismo tiempo, tienen que ser puntos de partida hacia otras construcciones teóricas. Sin duda se requiere entender la realidad con espíritu creativo e innovador, con nuevas perspectivas ecológicas, económicas y sociales.

\section{Resultados}

A lo largo de la historia, empresas y organizaciones se han ido adaptando y desarrollado; han estado sujetas a incesantes presiones de la sociedad, entre las que destaca la demanda hacia la participación en la toma de decisiones, la autogestión y flexibilidad en el trabajo.

De esta manera, organizaciones y empresas buscan articular sus objetivos e intereses; sin embargo, las divergencias y convergencias entre la administración pública y la privada, entre organizaciones y empresas, han sido muy variables en la historia.

En la actualidad, pareciera que la tradicional rivalidad existente entre administración pública y privada tiende a disminuir, e incluso parecen existir más convergencias que divergencias entre ambas. En la medida en que las empresas y las organizaciones rompan o flexibilicen sus estructuras y relaciones, nos brindarán nuevos modelos administrativos, nuevas redes de cambio, mapas cognoscitivos con posibilidades de abrir los objetivos económicos hacia metas colectivas, e incluso es posible que se pierdan los límites entre empresas públicas y privadas. Desde esta perspectiva, lo privado no lo es tanto, en la medida en que se inserta en el espacio público, en un espacio de convergencias de intereses comunes (Bozeman, 1987). 


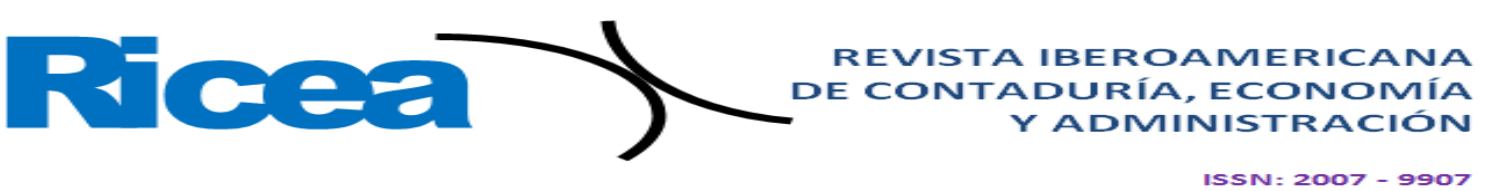

En el siglo XXI se están generando nuevos sistemas intencionalmente establecidos de empresas y organizaciones según la naturaleza de su entorno, de sus productos o servicios (sobre todo los burocráticos), controlados y supervisados por áreas jurisdiccionales. Estas redes interorganizativas e interempresariales serán cada vez más necesarias y obligarán a directivos de empresas y organizaciones a que establezcan contactos entre sí que conduzcan a reconstruir los sectores económicos y sociales más vulnerables de un país.

Estos imponentes cambios deberán ser articulados por los gerentes y administradores del siglo XXI. Ello hará necesaria la formación de un nuevo tipo de administrador de empresas y organizaciones, legitimado por las normas y los valores de la sociedad y por los valores éticos de su desempeño profesional.

Aunado a ello, actualmente las redes empresariales y organizacionales se revelan como redes ocultas, derivadas naturalmente de la dinámica del poder, del posicionamiento de las empresas y de las ventajas que pueden lograr de las organizaciones. Tal es el caso de las empresas transnacionales contemporáneas, del crimen organizado y de la articulación del narcotráfico con las redes gubernamentales.

De la misma forma, en las posiciones o cargos de gerentes y funcionarios prevalecen las prácticas de la tradición burocrática, de la sumisión a los objetivos subordinados y de la ausencia de valores y objetivos sociales.

Una vez más: en la medida en que las empresas y las organizaciones rompan o flexibilicen sus estructuras y relaciones, surgirán una serie de acuerdos de colaboración como fusiones, consorcios, alianzas estratégicas (joint-venture), concesión de licencias, patentes y marcas, acuerdos de fabricación, aprovisionamiento y marketing.

Estas nuevas redes estarán formadas por constelaciones de empresas vinculadas entre sí: por alianzas estratégicas de organizaciones burocráticas y no burocráticas; por redes de organizaciones civiles para la realización de tareas sociales; por conglomerados de organizaciones internacionales, gubernamentales y no gubernamentales con asociaciones de empresas, para reconstruir las zonas del mundo más afectadas ecológica, económica y socialmente.

En pleno siglo XXI nos encontramos a la espera de nuevos paradigmas para las empresas y las organizaciones. Sentimos que se acerca una época de profundas transformaciones. Sin embargo, en el contexto mundial, y particularmente en el latinoamericano, en el cual nos encontramos, es necesario entender la realidad con espíritu creativo e innovador con nuevas perspectivas ecológicas, económicas y sociales. 


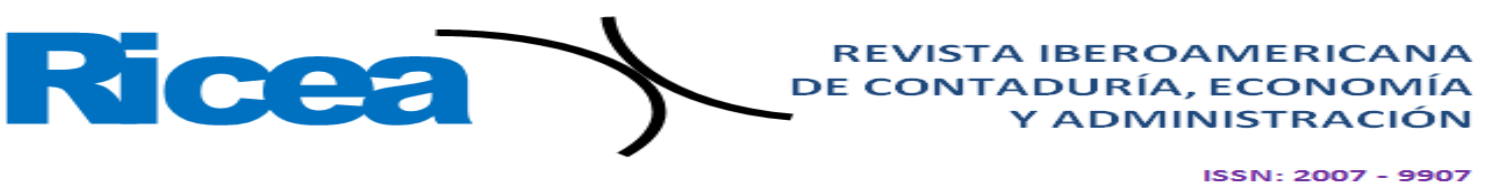

Para concluir este apartado, podemos decir que, a pesar de su importancia, el término administración sigue siendo vago y confuso. No obstante, se debe buscar un concepto para la administración cuya validez sea universal y que sus postulados realmente satisfagan al ser humano.

En la antigüedad clásica, los griegos denominaron a la administración con el concepto de oikos, que literalmente ha sido traducido como 'economía del hogar o de la casa', pero que si lo llevamos a la actualidad correspondería a la labor de los paterfamilias, es decir, administrar los bienes del hogar que en ese tiempo incluía no solo a la familia nuclear, sino también a los esclavos, las propiedades, el ganado, etc.

Los griegos (Jenofonte, 1999, pp. 161-210) concebían a la administración como una episteme, es decir, como un objeto de conocimiento en donde tienen cabida la ciencia y la filosofía. Para ellos, la administración no solo consistía en encontrar las técnicas más adecuadas para conservar, mantener, acrecentar los bienes y así garantizar la producción y reproducción de la vida de los miembros del hogar, o de los miembros de la sociedad, ya que, tratándose de la administración pública, en ello recae una responsabilidad ética, porque si se administran mal los bienes del hogar o de la sociedad, las consecuencias son graves en ambos casos, y no se estarían reproduciendo las condiciones de vida, de la familia y de la sociedad, y por lo tanto, no se estaría actuando conforme a la ética.

A su vez, los griegos acuñaron una tesis filosófica que establece que entre la administración pública y la privada existe una relación dialéctica, la cual se puede sintetizar así: Entre la administración del estado (la administración pública) y la administración del hogar (administración privada) existe un círculo virtuoso o vicioso, de manera tal que si la administración de la casa funciona mal, esto afecta a la administración del estado, porque recibirá menos contribuciones o impuestos, lo cual afectará sus funciones, pero si la administración del estado anda mal, si se dilapidan y se hace mal uso de los recursos públicos, esto repercutirá en la administración del hogar (empresas privadas), lo cual tiene un peso mayor de afectación en el bienestar de vida de los integrantes de un país, de una sociedad.

En este sentido es válido preguntarnos cuál ha sido la situación que guarda este vínculo entre las dos administraciones en México o en los países latinoamericanos. ¿De qué manera se establece un círculo virtuoso o vicioso en la historia de las naciones? ¿Cuándo existe correspondencia y colaboración, se logran mejores niveles de desarrollo y bienestar? ¿Cuáles son los 10 países con índice de desarrollo humano (IDH) más alto y bajo? ¿En qué posición se encuentra México en el IDH? ¿Qué grado de articulación existe entre lo público y lo privado en los países con mayor IDH? 


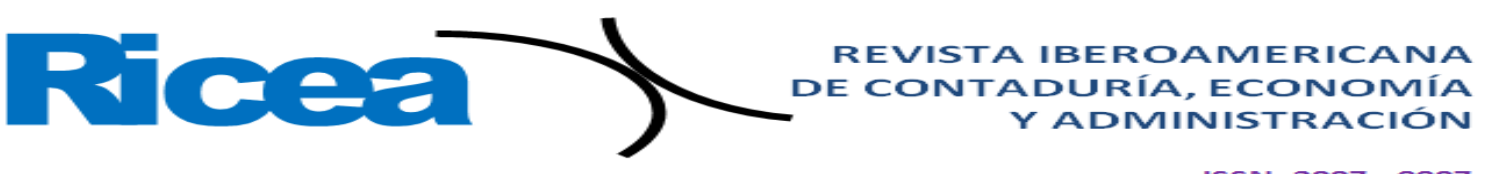

Cabe aclarar que el IDH fue creado como tal por el Programa de las Naciones Unidas para el Desarrollo (PNUD) y consiste, como su nombre lo indica, en determinar la cantidad o nivel de desarrollo humano que poseen los países del mundo. El desarrollo humano se caracteriza más por el potencial creativo y emprendedor de los ciudadanos que por el ingreso económico de estos.

En esto se basa principalmente la articulación de lo público con lo privado que fomenta el desarrollo emprendedor. La estimulación principal para lograr maximizar estas opciones es construyendo y fortaleciendo las capacidades necesarias humanas como, por ejemplo, promover la salud, educación, el empleo, el lograr conseguir recursos básicos y sustentables, la libertad, la independencia, la soberanía, entre otras; todas ellas forman parte de las políticas a partir de las que el IDH se construye y un país crece.

\section{Conclusiones}

Hoy en día la teoría administrativa debe manifestar la preocupación y el deseo implícito de construir un universo que no solo sea algo mejor y más racional que el que impera en el mundo actual. El poder de la administración y la administración del poder deben surgir de una base consensuada. La sociología administrativa del siglo XXI debe acudir al rescate de los valores del hombre administrativo, que administra para reproducir el patrimonio de su familia, de su sociedad, de su país, del mundo, de la humanidad.

El estudio de las empresas y organizaciones no solo debe enfocarse a la investigación de la racionalidad técnica, instrumental, sino también debe adentrarse en los aspectos simbólicos, cognitivos y culturales que permitan el diseño y la creación de nuevos modelos administrativos más acordes con las exigencias del tercer milenio.

Una administración crítica no solamente debe funcionar con base en el desempeño de los fines, sino que también debe intentar desarrollar la posibilidad de hacer compatible la producción y el desarrollo pleno de la vida, además de hacer que todos participen en este proceso.

Este problema representa la necesidad de establecer una nueva práctica docente que induzca a cultivar métodos educativos y estrategias pedagógicas de reflexión y de crítica para la superación de los obstáculos epistemológicos por medio de un estudio sistemático de la administración, cuya complejidad requiere el concurso de varias disciplinas (análisis interdisciplinario).

En la perspectiva crítica de la administración no se ha logrado todavía la conformación de un paradigma sistemático que cuestione al modernismo y al posmodernismo. Existen, sin embargo, un conjunto de pequeños paradigmas o intentos 
de posparadigmas empresariales y organizacionales a través de los cuales se pueden desarrollar metodologías de estudio, proceso de aprendizaje comprometidos con los modelos de equipo-compañerismo, comunitarios y de aprendizaje ecológico.

El concepto de capital social emerge como uno central para analizar los factores contextuales y locales que permiten la sustentabilidad de la economía para atenuar la pobreza, marginación y migración del campo a la ciudad.

En búsqueda del deber ser, la administración debe investigar, trabajar, proponer, ofrecer alternativas de solución conforme al parámetro de la ética, para administrar la vida en las empresas y organizaciones, y contribuir al proceso de desarrollo sustentable, y así garantizar que las generaciones futuras cuenten con los recursos necesarios para su pleno desarrollo. La teoría administrativa comparte el mismo paradigma de las ciencias sociales y, en nuestro caso, se trata de la búsqueda de un principio cuya validez sea universal, en donde sus postulados verdaderamente satisfagan al hombre. 


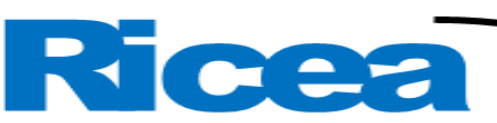

\section{Referencias}

Argyris, C. (1964) Personalidad y organización. México: Centro de Formación y Perfeccionamiento de Funcionarios.

Ballina, F. (2001). Teoría de la administración: un enfoque alternativo. México: McGraw-Hill.

Barnard, C. I. (1975). Las funciones de los elementos dirigentes. Madrid.

Barthes, R. (1994). El susurro del lenguaje: más allá de las palabras y la escritura. Barcelona, España: Paidós.

Baudrillard, J. (1978). A la sombra de las mayorías silenciosas. Madrid, España: Kairos. Baudrillard, J. (1985). La izquierda divina. Barcelona, España: Anagrama.

Baudrillard, J. (2002). Cultura y simulacro. Madrid, España: Kairos.

Baudrillard, J. (2004). Las estrategias fatales. Barcelona, España: Anagrama.

Baudrillard, J. (2006a). El otro por sí mismo. Barcelona, España: Anagrama.

Baudrillard, J. (2006b). El crimen perfecto. Barcelona, España: Anagrama.

Bell, D. (1977). Las contradicciones culturales del capitalismo. Madrid, España: Alianza Editorial.

Boje, D. and Dennehys, R. (1993). Managing in the postmodern world (1 ${ }^{\text {st }}$ Ed.). Dubuque, United States: Kendall/Hunt.

Boje, D., Gephart, R. P. and Thatchenkery, T. J. (eds.) (1996). Postmodern Management and Organization Theory. London, England / New Delhi, India: Thousand Oaks Sage.

Bourdieu, P. (1997). Capital cultural, escuela y espacio social. México: Siglo XXI.

Bozeman, B. (1987). Todas las organizaciones son públicas. (Tendiendo un puente entre las teorías corporativas privadas y públicas). México: FCE.

Cruz, F. (1988). Teoría administrativa. Bogotá, Colombia: McGraw-Hill.

Cruz, L. (2013). El concepto de poder en la administración. Contaduría y administración, $58(4)$.

Deleuze, G. y Guattari, F. (1993). Qué es la filosofía. Barcelona, España: Anagrama.

De Saussure, F. (1987). Curso de lingüística general. Madrid, España: Alianza editorial Dessler, G. (1993). Organización y administración (2. a ed.). México: Prentice-Hall.

De Ventós, X. (1980). Crítica de la modernidad. Barcelona, España: Anagrama.

Drucker, Peter F. (Peter Ferdinand), c1993, author Post capitalist society / New

York: Harper business,

Drucker, Peter F. (Peter Ferdinand), 1990, Las nuevas realidades en el estado y la política, en la economía y los negocios, en la sociedad y en la imagen del mundo Buenos Aires. Sudamericana; México: Hermes. 


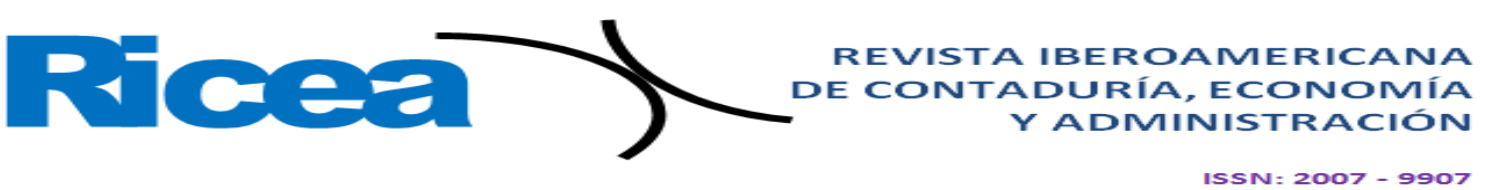

Drucker, Peter F. (Peter Ferdinand), 1994. autor La sociedad post-capitalista, Barcelona México: Norma,

Drucker, Peter F. (Peter Ferdinand), c1999. Los desafíos de la administración en el siglo XXI/ Buenos Aires: Sudamericana,

Drucker, Peter F. (Peter Ferdinand), 1909-2005, author managing the non-profit

Organization: Practices and principles / New York: Harper Collins, c1990.

Fayol, H. (1973). Administración industrial y general. México: Herrero.

Foucault, M. (1970). La arqueología del saber. Buenos Aires, Argentina: Siglo XXI editores.

Fromm, E. (1997). El miedo a la libertad. Buenos Aires, Argentina: Paidós.

Guzmán, I. (1966). La ciencia de la administración: la dirección de los grupos humanos. México: Limusa.

Habermas, J. (1993). Ciencia y técnica como “ideología”. México: REI.

Habermas y la modernidad. (1993). México: REI.

Homans, G. (1950). The human group. New York, United States: Harcourt, Brace and World.

Jameson, F. (1984). Postmodernism, or the cultural logic of late capitalism. New Left Review, 146, 53-93.

Jenofonte. (1999). Socrática. Economía. Ciropedia. España: Océano.

Jo Hatch, M. (1997). Organization theory, modern, symbolic, and postmodern perspectives. Oxford, United Kingdom: Oxford University Press.

Koontz, H. (1994). Curso de administración moderna, un análisis de sistemas y contingencias de las funciones administrativas. México: McGraw-Hill.

Koontz, H., Weihrich, H. y O’Donnell, C. (1991). Elementos de administración (4. a ed.). México: McGraw-Hill.

Lacan, J. (2008). El seminario de Jacques Lacan (libro 2). Buenos Aires, Argentina: Paidós.

Lewin, K. (1951). Field Theory of Social Science. Nueva York, United States: Harper and Row.

Leví-Strauss, C. (1964). El pensamiento salvaje (1. ${ }^{\mathrm{a}}$ ed.). México: FCE.

Lewin, K. (1968). Psychologie dynamique : Les relations humaines. Paris, France : Presses Universitaires de France.

Lilienthal, D. (1967). Management: A Humanist Art. Nueva York, United States: Columbia University Press.

Mannheim, K. (1982). Libertad, poder y planificación democrática. México: FCE. 
Merton, R. K. (2002). Teoría y estructura sociales (4. ${ }^{a}$ ed.). México: FCE.

Michels, R. (1968). Los partidos políticos (tomos I y II). Buenos Aires, Argentina: Amorrortu.

Mill, J. (2006). Principios de economía política. México: FCE.

Mills, C. W. (1961). La imaginación sociológica. México: FCE.

Mills, C. W. (1957). La élite del poder (1. ${ }^{\mathrm{a}}$ ed.). México: FCE.

Montaño, L. (2004). Las aproximaciones organizacionales caracterización, objeto y problemática. Revista de Contaduría y Administración, (213).

Parker, M., Metcalf, H. C. and Urwick, L. (eds.) (1942). Dynamic Administration: The Collected Papers of Mary Parker Follett. New York, United States: Harper \& Brother Publishing.

Reed, M. (1992). The Sociology of Organizations: Themes Perspectives and Prospects. London, England: Harvester-Wheatsheaf.

Ríos, J. (1990). La realidad cultural nacional y el estudio de la administración en México. México: FCA UNAM.

Senge, P. M. (1997). La quinta disciplina. Barcelona, España: Garnica.

Simón, H. (1988). El comportamiento administrativo. Estudio de los procesos decisorios en la organización administrativa. Buenos Aires, Argentina: Ed. Aguilar.

Sprott, W. J. H. y Johnson, H. M. (1968). Sociología y psicología social de grupo. Buenos Aires, Argentina: Paidós.

Taylor, F. (1978). Principios de la administración científica. México: Herrero.

Weber, M. (1969). Teoría de las categorías sociológicas. En Economía y sociedad (tomo II) (pp. 753-755). México: FCE.

Weber, M. (1977). Estructuras de poder. Buenos Aires, Argentina: La Pléyade. 